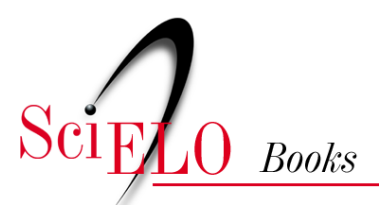

\title{
37. Mal de Engasgo e Doença de Chagas: A Solução de um Quebra-cabeças
}

\author{
Joffre Marcondes de Rezende
}

\section{SciELO Books / SciELO Livros / SciELO Libros}

REZENDE, J. M. Mal de Engasgo e Doença de Chagas: A Solução de um Quebra-cabeças. In: À sombra do plátano: crônicas de história da medicina [online]. São Paulo: Editora Unifesp, 2009, pp. 307-324. História da Medicina series, vol. 2. ISBN 978-85-61673-63-5. https://doi.org/10.7476/9788561673635.0038.

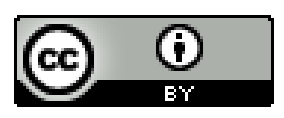

All the contents of this work, except where otherwise noted, is licensed under a Creative Commons Attribution 4.0 International license.

Todo o conteúdo deste trabalho, exceto quando houver ressalva, é publicado sob a licença Creative Commons Atribição 4.0.

Todo el contenido de esta obra, excepto donde se indique lo contrario, está bajo licencia de la licencia Creative Commons Reconocimento 4.0. 


\section{Mal de Engasgo e Doença de Chagas: A Solução de um Quebra-cabeças*}

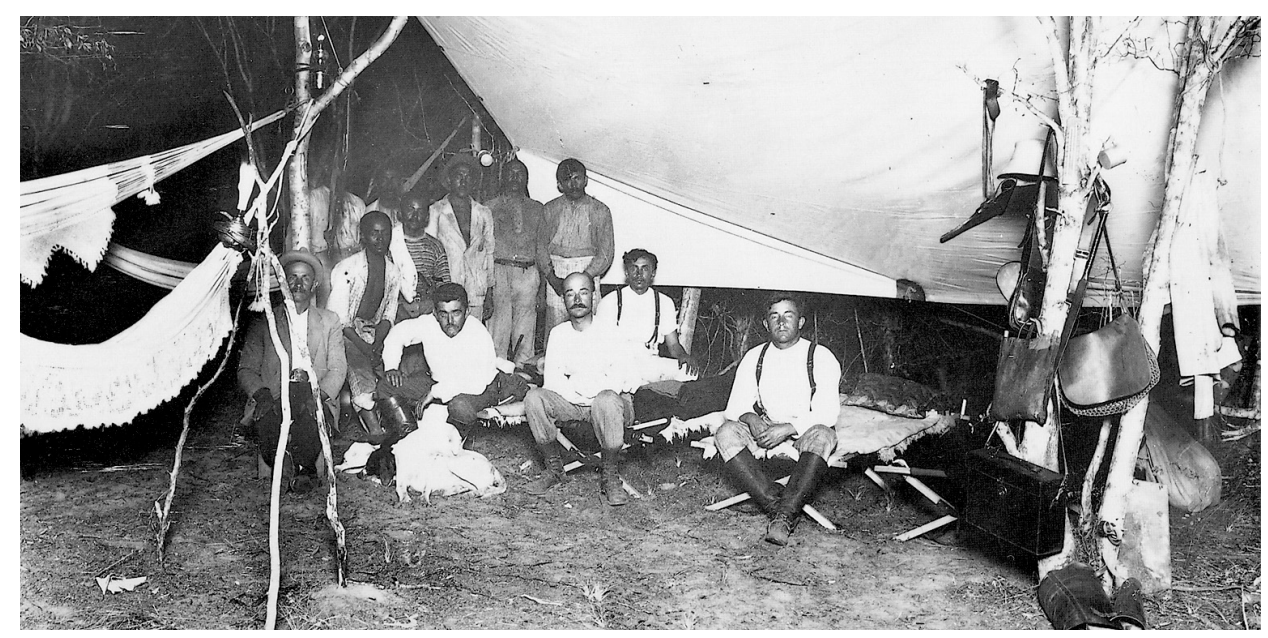

Ao centro, sentados, Belisário Penna e Arthur Neiva, no interior do Piauí, junho de I9I2.

$\mathrm{D}$

esde o período colonial que se conhece no Brasil uma doença de caráter endêmico que acomete as populações rurais de determinadas áreas geográficas, caracterizada pela dificuldade de deglutir os alimentos e, por isso mesmo, popularmente denominada de mal de engasgo.

Embora haja menção a sintomas que poderiam ser atribuídos a esta afecção já no século XVIII, as primeiras publicações que se referem expressamente ao mal de engasgo datam do século XIX.

A primeira delas encontra-se na obra dos naturalistas alemães Spix e Martius, intitulada Von Reise in Brasilen (Viagem pelo Brasil) publicada em I 823. Casos dessa afecção foram encontrados nos Campos Gerais de São Felipe, sertão da Bahia, e na viagem em direção a Oeiras, no sul do Piauí (Spix e Martius, I98I, pp. 97 e 240).

* Modificado da conferência proferida na Academia Mineira de Medicina em 25 de novembro de I999, publicada no livro Vertentes da Medicina, São Paulo, Giordano, 200 I. 
A segunda referência se deve aos missionários norte-americanos Daniel Kidder e James Fletcher, no livro Brazil and the Brazilians, cuja primeira edição data de I 857 e, a oitava, de I879, havendo uma tradução brasileira da sétima edição, de I867, publicada em I94I pela Companhia Editora Nacional, na Coleção Brasiliana (Kidder e Fletcher, I94I, pp. I27-I28).

Neste livro os autores apresentam o mal de engasgo como uma nova doença peculiar ao nosso país, da qual tomaram conhecimento em Limeira, no estado de São Paulo, no consultório de um médico que ali clinicava. Os autores não revelaram o nome do citado médico e sua identidade só foi descoberta recentemente. Trata-se de Joseph Cooper Reinhardt, de nacionalidade norte-americana, que residiu em Limeira e, posteriormente, transferiu-se para Campinas, onde faleceu em I 873, aos 63 anos de idade (Meneghelli et al., I998, pp. I-8).

$\mathrm{Na}$ sequência cronológica dos registros, a próxima referência ao mal de engasgo se deve a Alfred de Taunay, engenheiro militar e escritor, que tomou parte na guerra do Brasil com o Paraguai. Em sua memória "Viagem de Regresso de Mato-Grosso à Corte”, publicada em I869 na Revista do Instituto Historico, Geographico e Ethnografico do Brasil, refere-se ao mal de engasgo como "moléstia que lavra no sertão em concorrência com as feridas bravas e as maleitas" (Taunay, I 869, pp. 5-5I). No seu clássico romance Inocência descreve com mais detalhes o sofrimento de um doente de mal de engasgo (Taunay, I97I, pp. I 54-I 55). Segundo Meneghelli, os personagens deste romance foram, sem dúvida, inspirados em personagens reais que Taunay conheceu em suas viagens pelo interior do país (Meneghelli et al., op. cit.).

$\mathrm{Na}$ literatura médica, a primeira descrição do mal de engasgo encontra-se no Diccionario de Medicina Domestica e Popular, de autoria de Theodoro Langgaard, médico dinamarquês emigrado para o Brasil e que residia em Campinas, no estado de São Paulo.

Na segunda edição do Diccionario, datada de I873, Langgaard, ao se referir ao mal de engasgo, escreve: "Esta afecção existe há muito endemicamente na província de Goiás, mas nos últimos anos tem se estendido a uma certa região de Minas Gerais e entrado na província de São Paulo na parte que confina com essas províncias e presentemente encontra-se com muita frequência em uma região que de Franca se estende a São Simão, Araraquara e municípios vizinhos" (Langaard, I 873). 
Outra notícia sobre a afecção encontra-se na obra Geographia Physica do Brasil, de Wappaeus, edição de I 884 . Trata-se de uma tradução condensada e refundida do texto original alemão, e a informação sobre o mal de engasgo se deve a Martins Costa. Está assim redigida: "Há também nessas regiões (Curvelo, MG) uma moléstia endêmica a que os habitantes chamam de mal de engasgo, o qual consiste, segundo o dr. Ildefonso Gomes em uma paralisia da faringe; os que padecem essa moléstia não podem engolir os alimentos, cada bolo de comida é empurrado por alguns goles de água" (Costa, I884, pp. 204-205).

Conforme assinalaram Porto e Porto (1970, pp. I I7-I36), o interesse pelo estudo do mal de engasgo aumentou com a introdução dos raios-X na prática médica no final do século passado e com a fundação da Sociedade de Medicina e Cirurgia de São Paulo em I 895.

Na primeira sessão daquela Sociedade, realizada em Io de abril de I 895 , por proposta de Bittencourt Rodrigues, o mal de engasgo foi escolhido como um dos assuntos a serem debatidos e estudados. Nesta e nas sessões subsequentes manifestaram-se sobre o mal de engasgo Marcos Arruda, Carlos Botelho, Diogo de Faria, Vieira de Carvalho, Sérgio Meira Filho, Pedro de Rezende, Tiberio de Almeida, entre outros (Parisi, I925).

Dentre os membros da Sociedade partidários de etiologia própria para o mal de engasgo estavam Carlos Botelho e Pereira Barreto. Em correspondência dirigida a Sérgio Meira Filho, que se encontra transcrita por Enjolras Vampré sem menção à data, Botelho assim se expressou: “[...] a etiologia não pode deixar de ser parasitária ou pseudomalárica, com localização nas vizinhanças do cárdia" (Vampré, I9I9, pp. 3-78). Na mesma carta refere-se ao mal de engasgo como "disfagia tropical, nome que proponho à moléstia, porque esta última palavra traz-nos à mente, sempre, uma insinuação parasitária”.

Pereira Barreto, em carta datada de 27 de julho de I9I8, dirigida a Vampré, expressa seu ponto de vista com base em experiência pessoal: "Das minhas observações de mais de quarenta anos resulta que todos os doentes de mal de engasgo sem exceção, tiveram anteriormente maleitas. É irrefragável o vínculo que prende o mal de engasgo ao impaludismo. O mal de engasgo, portanto, deve ser forçosamente moléstia parasitária" (Idem, ibidem).

Em I9 2, Arthur Neiva e Belisário Penna, do Instituto Oswaldo Cruz, empreenderam uma expedição científica ao interior do Brasil por solicitação 
da Inspetoria de Obras contra a Seca. Percorreram a região norte da Bahia, sudoeste de Pernambuco, sul do Piauí e de norte a sul de Goiás. O relatório completo dos ilustres pesquisadores só foi publicado em I9I6 (Neiva e Penna, I9I6, pp. 74-224). É um repositório de valiosas informações sobre o clima, flora, fauna, condições de salubridade e doenças encontradas nas regiões visitadas. Dentre as doenças por eles observadas figura o mal de engasgo, que foi descrito com grande riqueza de dados quanto à sua epidemiologia, sintomas e associações mórbidas. O texto é ilustrado com as observações clínicas de dez pacientes que sofriam "entalação".

Os autores assinalaram a concomitância do mal de engasgo com a obstipação intestinal (caseira) e distúrbios do ritmo do coração (vexame). A ideia de que se tratasse de uma doença infecciosa levou-os a injetar sangue de pacientes com mal de engasgo em preás, sem qualquer resultado positivo. Discorreram sobre outras doenças existentes na região por eles percorrida, como a moléstia de Chagas, febre amarela, impaludismo, sem estabelecer qualquer vínculo das mesmas com o mal de engasgo.

Após a descoberta da tripanossomíase americana por Carlos Chagas, em I909, era natural que a doença de Chagas passasse a ser considerada como uma possível causa do mal de engasgo.

Já em I9I3 Ulysses Paranhos comenta esta hipótese no seguinte trecho de um artigo publicado em francês sob o título "Considérations sur le mal d'engasgo", escreve Paranhos, “[...] dans une conversation particulière, nous apprîmes que quelques médecins pensent que le 'mal d'engasgo' pourrait être une variété clinique de la Trypanosomiase de Chagas. Cependant, à ce quíl paraît, l'éxpérimentation n'a pas été possible de démontrer la présence de trypanosomes dans le sang des malades" (Paranhos, I9I3, pp. 47-50).

Paranhos aventou a possibilidade de uma causa tóxica proveniente do uso da mandioca como alimento.

Chagas, em I9I6, em seu clássico trabalho sobre a forma aguda da tripanossomíase americana, menciona a disfagia como uma das manifestações da doença e levanta a hipótese da etiologia chagásica do mal de engasgo. Reproduzimos a seguir o texto integral de seu trabalho onde se refere a essa possibilidade: 


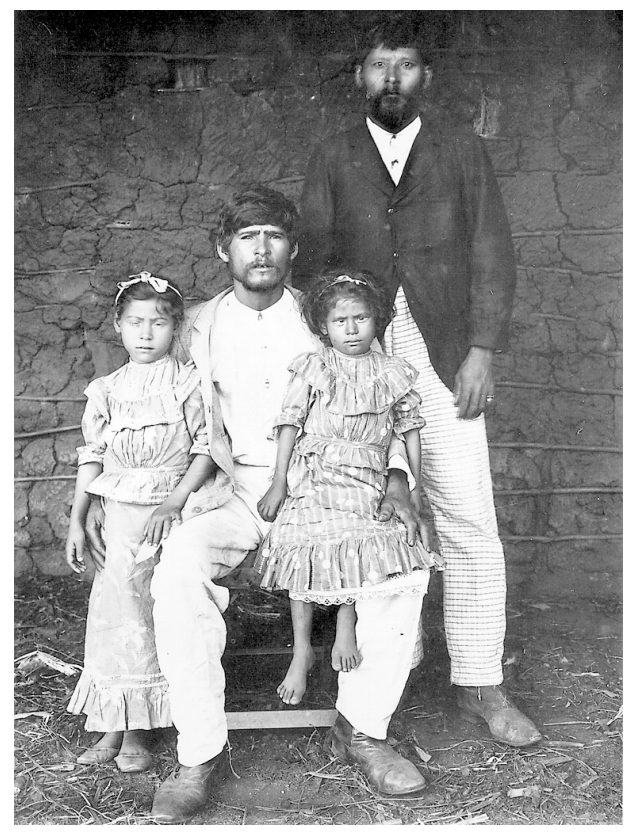

A expedição do Instituto Oswaldo Cruz ao interior do Brasil encontrou diferentes doenças durante seu percurso. Neste grupo, em Caracol (PI), o homem da direita sofre de "entalação", o outro, de ataques silenciosos, e as meninas, de conjuntivite granulosa.

Outro sinal que nos foi revelado por infecção aguda em adulto é o que se expressa em acentuada disfagia para os alimentos sólidos e também para os líquidos. A ingestão de substâncias sólidas exige, para se completar, o auxílio de água, referindo os doentes que o alimento fica retido no esôfago, trazendo sensações penosíssimas. Mesmo a ingestão de substâncias líquidas, e da própria água, pode apresentar dificuldades, não raro invencíveis, necessitando o artifício de deglutições cuidadosas e de pequenas parcelas do líquido.

Este sinal de patogenia ainda mal esclarecida, relaciona-se talvez com a condição de disfagia conhecida pelo nome de mal de engasgo, endemia extensa em regiões do interior do Brasil e, segundo nossas observações, verificada principalmente naquelas zonas onde é encontrada a tripanossomíase. Será o mal de engasgo um elemento mais da tripanossomíase brasileira e essa disfagia das formas aguda traduzirá a fase inicial da síndrome? Observamos no correr de nossos estudos em Lassance número bem elevado de doentes com mal de engasgo, havendo em todos eles outros sinais simultâneos da tripanossomíase. 
Apesar disso tornam-se precisas novas pesquisas que autorizem, de modo irrecusável, incluir o mal de engasgo na sintomatologia multiforme da infecção pelo Trypanosoma cruzi.

Neste mesmo trabalho encontra-se a primeira referência ao exame radiológico do esôfago em pacientes de mal de engasgo, realizado pelo dr. Leocadio Chaves: "Em doentes que apresentavam a síndrome muito acentuada, o dr. L. Chaves verificou, pela radiografia, a existência de considerável ectasia do esôfago, situada logo acima do cárdia" (Chagas, I916, pp. 37-69).

Em i9ı9, Vampré publicou o estudo radiográfico de três casos de mal de engasgo utilizando contraste à base de bismuto como era usual na época. Demonstrou que:

[...] a dificuldade de deglutição só se estabelece quando os alimentos devem passar do esôfago para o estômago na última fase da deglutição. [...] No mal de engasgo o esôfago examinado aos raios-X toma o aspecto de uma grande bolsa onde ficam acumulados os alimentos. A dilatação do esôfago é secundária e vai se estabelecendo pela dificuldade que têm os alimentos de chegar ao estômago (Vampreé, op. cit.).

Atribuiu essa dificuldade a um espasmo do diafragma, teoria que abandonou posteriormente em vista da ineficácia da secção dos pilares do diafragma como forma de tratamento cirúrgico da afecção (Vampré, I923, pp. I37-I 58 ).

Na década de I920 houve um arrefecimento no interesse pelos estudos sobre o mal de engasgo. Deve ser mencionado, no entanto, o trabalho de Chagas e Villela, de I922, no qual os autores referem a ocorrência de mal de engasgo em quatro dentre 63 pacientes chagásicos por eles estudados (Chagas e Villela, I922, pp. 5-6I).

Os estudos sobre mal de engasgo foram retomados na década de I930 por pesquisadores paulistas. O ponto de partida pode ser fixado em I932, com o trabalho de Amorim e Correa Neto (I932, pp. IOI-I 27), no qual estes autores descreveram lesões do plexo mioentérico não somente no esôfago e no cólon, mas também em todo o trato digestivo. 
Seguem-se as pesquisas de Etzel (1934, pp. 63I-650) e de Correa Neto e Etzel (1934, pp. 395-420), que demonstraram a identidade etiopatogênica entre as lesões encontradas no esôfago e no cólon de portadores de mal de engasgo e o caráter sistêmico da afecção, acometendo todo o trato digestivo.

As lesões do plexo mioentérico foram descritas com detalhes e aceitou-se a teoria da acalásia de Hurst como base fisiopatológica da dilatação tanto do esôfago como do cólon. A denominação de "mal de engasgo", que vinha sendo usada na terminologia médica, foi substituída por "megaesôfago", que, apesar de imprópria, iria prevalecer ao lado de "megacólon" (Correa Neto, 1935).

Diversos outros trabalhos foram a seguir publicados, acrescentando novos dados e evidenciando novos aspectos relacionados com o megaesôfago e o megacólon. Correa Neto (1934, pp. 72 I-735) mostrou a associação frequente de ambas as condições; Etzel (I935, pp. 59-85) verificou a existência de hipocloridria em pacientes com megaesôfago; Correa Neto (I940, pp. I48-I 53) e Raia (I943) descreveram a "acalásia” do piloro como manifestação frequentemente associada ao megaesôfago e megacólon; Ramos e Oria (1940, pp. 363-442), descreveram lesões dos sistema nervoso autônomo do coração em pacientes com megaesôfago, estabelecendo, assim, um vínculo etiopatogênico desta afecção com a cardiopatia crônica a que está frequentemente associada. Nessa cardiopatia, as alterações eletrocardiográficas superpunham-se às encontradas na cardiopatia chagásica crônica, conforme se pode verificar no trabalho de Ramos (I935, pp. I49-I6I).

Os dados disponíveis já permitiam a unificação etiológica da cardiopatia chagásica crônica com os megas digestivos. Todavia, Etzel, em I935, postulara como possível causa do megaesôfago e megacólon, a avitaminose BI, que acompanha a desnutrição crônica, teoria que teve boa acolhida nos meios científicos do país e do exterior.

Conforme depõe o prof. Paulo de Almeida Toledo (r975, pp. 266-276), havia na época pouco interesse pela moléstia de Chagas na capital paulista. Os primeiros trabalhos sobre a moléstia começaram a aparecer em São Paulo a partir de I939. "Até então, os aspectos clínicos da tripanossomíase eram quase completamente desconhecidos em nosso meio médico e muitos casos observados nas enfermarias, de miocardite de origem obscura, eram rotulados de beribéri, na falta de melhor diagnóstico". 
Desde I9I 3 dispunha-se de uma reação sorológica para a doença de Chagas, descrita por Guerreiro e Machado, e era natural que a mesma fosse empregada na investigação da prevalência da doença de Chagas na população de áreas endêmicas, assim como em pacientes de mal de engasgo.

A primeira pesquisa nesse sentido data de I930 e deve-se a Eurico Villela no seu trabalho intitulado: "A Ocorrência da Moléstia de Chagas nos Hospitais de Belo Horizonte e na População de seus Arredores" (Villela, I930, pp. I22-I 56). Em I 86 pessoas investigadas, 53 (28,5\%) tinham a reação de Guerreiro e Machado positiva, ao passo que em treze pacientes de mal de engasgo, oito apresentaram reação positiva (6I,3\%). Apesar da pequena casuística, Villela conclui: "Deve haver uma síndrome de disfagia provocada pela tripanossomíase americana".

Em I934, também em Belo Horizonte, em seu trabalho Cardiospasmo (Mal de Engasgo), dedicado ao prof. Octaviano de Almeida, A. Melo Alvarenga (I934) realizou a reação de Guerreiro Machado em dezesseis casos de mal de engasgo, encontrando-a positiva em oito $(50 \%)$, o que o levou a concluir, do mesmo modo que Eurico Villela, que "a tripanossomíase americana deve ser responsabilizada como uma das causas determinantes do cardiospasmo".

Entre I939 e 1942, Martins, Versiani e Tupinambá (1945, pp. 63-70) realizaram xenodiagnóstico em ${ }_{5} 6$ pacientes selecionados em vários hospitais e clínicas de Belo Horizonte, dentre os quais 63 com miocardite, 48 com megaesôfago e $28 \mathrm{com}$ bócio. A positividade dos xenodiagnósticos foi de $36,5 \%$ nos casos de miocardite, $45,8 \%$ nos casos de megaesôfago e apenas $\mathrm{I} 7,8 \%$ nos casos de bócio.

Este trabalho tem um valor especial por ser o primeiro estudo parasitológico comparativo entre pacientes com bócio e megaesôfago. A análise dos dados mostra diferença estatisticamente significativa entre o número de exames positivos obtidos nos casos de megaesôfago e de bócio.

O bócio endêmico fora considerado inicialmente uma das manifestações da doença de Chagas, o que levou Miguel Pereira a propor para a tripanossomíase americana a denominação de "tireoidite parasitária", denominação esta que chegou a ser usada por Carlos Chagas (I981, pp. I67-I92) em sua conferência na Academia Nacional de Medicina, em i9 I I.

A inclusão do bócio endêmico como uma das manifestações da doença de Chagas baseou-se principalmente em dados clínicos e epidemiológicos. 
Uma vez comprovado que se tratava de mera superposição geográfica das duas endemias, o bócio foi retirado da patologia da doença de Chagas, porém o episódio constituiu-se em arma da qual se valeram os detratores de Carlos Chagas na campanha de descrédito capitaneada por Afrânio Peixoto contra o grande feito do genial pesquisador mineiro.

Além disso, o episódio influenciou negativamente nos estudos da correlação etiológica entre doença de Chagas e o mal de engasgo. Temia-se a repetição do equívoco da superposição de áreas endêmicas, sobretudo considerando a inexistência de megaesôfago e megacólon em outros países com elevada prevalência da doença de Chagas.

Acrescente-se, ainda, a similaridade do megaesôfago chagásico com a acalásia idiopática, ambos, até então, interpretados como uma mesma e única doença, o que tornava ainda mais temerária a aceitação da doença de Chagas como causa do nosso mal de engasgo.

Dois outros importantes estudos foram realizados em Minas Gerais, direcionados para a doença de Chagas na infância. Nunan, Rezende e Canelas (1952, pp. 633-636), em I952, revendo em Bambuí treze crianças nas quais fora antes diagnosticada a fase aguda da doença de Chagas, encontraram quatro com megacólon.

Rezende, Pellegrino e Canelas (1953, pp. 24I-250), em inquérito realizado em um total de duzentas crianças internadas em hospitais de Belo Horizonte, encontraram catorze com reações sorológicas positivas para doença de Chagas, das quais cinco apresentavam megaesôfago e ou megacólon.

A ocorrência de megaesôfago e megacólon em crianças infectadas pelo T. cruzi era um dado a mais a indicar claramente a participação do trato digestivo na complexa patologia da doença de Chagas.

Referência especial deve ser feita à contribuição dada à questão pelos médicos de Uberaba, Uberlândia e Araguari.

Os congressos médicos do Triângulo Mineiro e Brasil Central, realizados entre I947 e 1956, constituíram-se em foro de debates sobre a etiologia chagásica do megaesôfago e megacólon endêmicos (Porto e Porto, op. cit.). Enquanto os clínicos e cirurgiões da região defendiam a etiologia chagásica, com base em dados clínicos e epidemiológicos, professores de outros centros, especialmente de São Paulo, argumentavam contrariamente alegando superposição de áreas endêmicas e falta de comprovação anatomopatoló- 
gica, e aceitavam a hipótese da avitaminose BI como causa da degeneração do plexo mioentérico existente nos megas. Insistia-se na necessidade do achado de células parasitadas pelo Trypanosoma cruzi nas paredes do esôfago e do cólon dilatados.

$\mathrm{O}$ aperfeiçoamento do antígeno utilizado na reação de Guerreiro e Machado possibilitou a obtenção de índices de positividade cada vez mais elevados nas reações sorológicas para doença de Chagas realizadas em pacientes com megaesôfago e megacólon.

Dois trabalhos se destacam por sua casuística e pelos resultados alcançados: o de Pedreira de Freitas (I947), com oitenta casos e 92,7\% de positividade, e o de Laranja, Dias e Nóbrega ( I948, pp. 473-529), com 8I casos e $97 \%$ de positividade.

O trabalho de Laranja, Dias e Nóbrega fora apresentado ao I Congresso Pan-americano de Medicina, realizado no Rio de Janeiro em setembro de I946, e apenas referido de passagem em artigo mais extenso sobre a doença de Chagas, publicado em I948. Em conversa com o dr. Francisco Laranja, por ocasião da IV Reunião de Pesquisa Aplicada em Doença de Chagas, realizada em Araxá, em I987, indagamos dele por que não havia publicado em separado e com o merecido destaque a investigação sorológica realizada em pacientes com megas. Ele nos respondeu que fora dissuadido de fazê-lo com o argumento de que poderia repetir-se, no caso do mal de engasgo, o episódio do bócio endêmico.

Em 1959 apresentamos ao Congresso Internacional sobre a Doença de Chagas, realizado no Rio de Janeiro, os resultados de nossas próprias observações. Em 332 casos de megaesôfago, 277 de cardiopatia e 593 crianças não selecionadas de área endêmica, obtivemos, respectivamente $89, \mathrm{I} \%$, $68,6 \%$ e I $8,2 \%$ de positividade (Rezende, I963, pp. I 407-I 426). Ouvimos, durante os debates, as mesmas objeções: que estes números nada provavam e que deveria tratar-se de simples coincidência.

Os argumentos para a rejeição da etiologia chagásica dos megas continuavam os mesmos de sempre:

I. O mal de engasgo é o mesmo cardiospasmo ou acalásia do esôfago, de ocorrência universal.

2. O mal de engasgo não é encontrado em todas as áreas onde a doença de Chagas é endêmica, como nos países da América Central. 
3. A associação do mal de engasgo com a doença de Chagas poderia ser explicada pela superposição geográfica das duas endemias, tal como no caso do bócio endêmico.

4. Nem todos os chagásicos evoluem com megaesôfago ou megacólon.

5. Ainda não havia sido demonstrado parasitismo nas paredes do esôfago ou do cólon que justificasse as lesões encontradas.

A partir de 1954, Koeberle e seus colaboradores, da Faculdade de Medicina de Ribeirão Preto, desenvolveram as pesquisas tão reclamadas, que levariam à comprovação anatomopatológica da ação do Trypanosoma cruzi no trato digestivo.

Fritz Koeberle, ao assumir a chefia do Departamento de Patologia da Faculdade de Medicina de Ribeirão Preto, foi surpreendido pela alta prevalência da doença de Chagas nos casos de autópsia e dedicou-se inteiramente ao estudo de sua patologia. Após adquirir noções básicas de português, o que conseguiu em pouco tempo em vista de seus conhecimentos de latim, inteirou-se da literatura brasileira sobre a doença de Chagas e os megas. De um lado, a indicação clínica, epidemiológica e sorológica da etiologia chagásica dos megas; de outro lado, a demonstração, desde os trabalhos de Amorim e Correa Neto e de Etzel, da existência de lesões degenerativas do plexo mioentérico do trato digestivo nos casos de megaesôfago e megacólon.

Cumpria, pois, comprovar a ação do Trypanosoma cruzi na parede muscular do trato digestivo, lesando o sistema nervoso intrínseco e causando dilatação do esôfago e do cólon. Em sucessivos trabalhos, Koeberle e seus colaboradores demonstraram haver na doença de Chagas lesões irreversíveis do sistema nervoso intrínseco, especialmente dos plexos intramurais do trato digestivo, acarretando alterações motoras cuja repercussão é mais evidente no esôfago e no cólon em razão provavelmente da fisiologia desses segmentos ${ }^{\mathrm{I}}$.

Por meio da contagem das células nervosas na parede do esôfago e do cólon em casos humanos de chagásicos autopsiados e em animais de experimentação, verificou Koeberle, de modo constante e em grau variável, uma redução dos neurônios daqueles plexos, especialmente do plexo mioentérico de Auerbach, ao longo de todo o trato digestivo.

I. Ver os diversos trabalhos de Koeberle ao final deste capítulo. 
A maior contribuição de Koeberle foi, sem dúvida, a de conceituar a doença de Chagas como doença do sistema nervoso autônomo, conceito este que se mostrou bastante fértil, ensejando as mais variadas pesquisas em chagásicos crônicos, com o objetivo de demonstrar a participação do sistema nervoso autônomo na fisiologia do trato digestivo e nos complexos mecanismos de homeostase orgânica (Rezende, I993, pp. I729-I755).

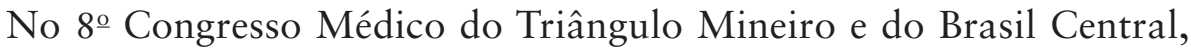
realizado em Uberaba, de 3 a 8 de setembro de 1956, Pedreira de Freitas ressaltou a importância das pesquisas de Koeberle no sentido de comprovar a etiologia chagásica do megaesôfago e do megacólon endêmicos no Brasil (Freitas, I956, pp. 31 5-320).

Nesse mesmo congresso, propusemos a revisão da classificação das formas clínicas da doença de Chagas para acrescentar a forma digestiva, "como forma clínica individualizada, nela se incluindo todas as lesões do tubo digestivo. [...] Fundamentamo-nos no fato de que, clinicamente, encontramos com grande frequência pacientes chagásicos com manifestações digestivas exclusivas e importantes, sem sinais clínicos ou eletrocardiográficos de comprometimento do coração" (Rezende, I956, pp. 297-3I4). Em trabalho posterior procuramos definir melhor a forma digestiva, nela incluindo "todas as desordens motoras, secretoras ou absortivas do aparelho digestivo, já descritas ou que venham a ser caracterizadas futuramente" (Rezende, I959, pp. 193-227).

No Congresso Internacional sobre a Doença de Chagas, realizado no Rio de Janeiro de 5 a I I de julho de I959, o prof. Koeberle apresentou o seu trabalho: "Moléstia de Chagas: Enfermidade do Sistema Nervoso" (Koeberle, I96 Ia, pp. 69 I-7I6). Além de críticas e comentários desfavoráveis, foi feita uma comunicação sobre o achado de megaesôfago em um macaco que havia sido inoculado dez anos antes com Trypanosoma cruzi. Tratava-se, na realidade, da produção experimental acidental do megaesôfago chagásico. Seus autores, do Hospital Evandro Chagas e, portanto, com a responsabilidade de pesquisadores do Instituto Oswaldo Cruz, concluíram:

I. A infecção chagásica pode determinar o megaesôfago.

2. O megaesôfago consequente à infecção chagásica independe de lesão estrutural dos plexos nervosos intramurais, para se instalar. 
3. O fator determinante na produção do megaesôfago chagásico parece ser a inflamação intersticial, destruição e fibrose da túnica muscular.

4. Um processo inflamatório e consequente fibrose particularmente intensos ao nível do cárdia devem facilitar ou condicionar a produção do megaesôfago, o que de certo modo explicaria a ausência desta lesão em doentes com evidentes focos inflamatórios em outras regiões do órgão que não aquela (Guimarães e Miranda, I96I, pp. 657-67I).

No plano internacional, no entanto, houve melhor aceitação dos trabalhos de Koeberle. No II Congresso Mundial de Gastroenterologia, realizado em Munique, na Alemanha, de I3 a I9 de maio de I962, a acalásia do esôfago foi tema de uma mesa redonda, na qual tomaram parte dez convidados de cinco países. Quatro dos participantes eram brasileiros: Geraldo Siffert, moderador; Fritz Koeberle, Joffre M. de Rezende e L.H. Câmara-Lopes.

O prof. Franz Ingelfinger, de Boston, que presidia a sessão, em seus comentários finais assim se referiu à contribuição brasileira ao tema:

Não é por acaso que quatro membros deste painel vieram do Brasil, pois, neste país, a doença esofagiana que estamos discutindo ocorre com uma prevalência jamais vista em outras áreas do mundo aqui representadas [...]. Assim, parece-me que podemos aceitar a variedade brasileira de acalásia como um modelo que nos indica um possível processo pelo qual os nossos próprios casos podem se desenvolver. Talvez nossos casos também sejam o resultado tardio de uma infecção ou infestação que lesa o plexo de Auerbach por um mecanismo tóxico ou, possivelmente, autoimune, e desapareça, não deixando vestígios quando os efeitos tardios da lesão neurológica finalmente se manifestam na forma de acalásia. Os brasileiros nos deram uma importante diretriz (Ingelfinger, I963, pp. 44-45).

Koeberle naturalizou-se brasileiro, revalidou seu diploma de médico no Brasil e jamais pensou em retornar à Europa após a sua aposentadoria.

$\mathrm{Na}$ década de I960, vários pesquisadores brasileiros confirmaram os achados de Koeberle em relação à desnervação do sistema nervoso entérico na doença de Chagas humana e experimental e acrescentaram novos aportes à compreensão da patogênese das lesões degenerativas dos plexos intramurais. Dentre as várias contribuições nesse sentido cumpre destacar 
as de autoria de Tafuri e Brener (1966, pp. 371-383), Tafuri, Maria e Lopes (r971, p. 76), Andrade e Andrade (1966, pp. 219-224) e Okumura (1967, pp. 192-203).

Menção especial deve ser feita a Aristóteles Brasil, cuja genialidade evidenciou-se em seus estudos clínicos e fisiopatológicos sobre a doença de Chagas. Sendo um cardiologista e trabalhando isoladamente, foi o primeiro a fazer registros manométricos trissegmentários do esôfago na esofagopatia chagásica, comprovando a incoordenação motora que caracteriza a perda do peristaltismo nesta afecção (Brasil, I955, pp. 2I-44). Propôs para o megaesôfago a denominação de aperistalsis, que chegamos a utilizar em um de nossos trabalhos (Rezende, Lauar e Oliveira, I960, pp. 247-262).

Os argumentos que se antepunham à aceitação da etiologia chagásica do megaesôfago e megacólon endêmicos foram sendo aos poucos removidos.

I. A semelhança com a acalásia idiopática passou a ser vista como decorrência da possibilidade de se tratar de uma mesma síndrome com etiologias distintas.

2. A distribuição geográfica do mal não coincidente com a da doença de Chagas passou a ser explicada pelas diferenças de cepas do Trypanosoma cruzi quanto à sua virulência e patogenicidade.

3. Os resultados das reações sorológicas com técnicas aperfeiçoadas demonstraram uma correlação altamente significativa entre megaesôfago e megacólon endêmicos com a doença de Chagas, afastando a hipótese de superposição geográfica das duas endemias.

4. A relativa baixa prevalência do mal de engasgo nas populações chagásicas (menos de $10 \%$ ) indica que a desnervação de menor intensidade encontrada por Koeberle na maioria dos chagásicos é compatível com uma função normal (Rezende, I993, pp. I729-I755).

5. Finalmente, o parasitismo da parede esofagiana é facilmente demonstrável na fase aguda da infecção e, na fase crônica, em que o parasitismo é escasso, também se podem encontrar pseudocistos de amastigotas após uma pesquisa mais elaborada.

Atualmente aceita-se como bem estabelecida a forma digestiva da doença de Chagas, na qual predomina o comprometimento do trato digestivo em 
relação ao coração e da qual o megaesôfago e o megacólon constituem as manifestações de maior significado clínico.

\section{Referências Bibliográficas}

Alvarenga, A. M. Cardiospasmo (Mal de Engasgo). Belo Horizonte, Imprensa Oficial do Estado de Minas Gerais, I934.

Amorim, M. \& Correa Neto, A. "Histopathologia e Pathogenese do Megaesophago e do Megarecto: Considerações em torno de um Caso de Mal e Engasgo". Anais da Faculdade de Medicina da Universidade de São Paulo, 8, pp. IOI-I27, I932.

Andrade, S. G. \& Andrade, Z. A. "Doença de Chagas e Alterações Neuronais no Plexo de Auerbach: Estudo Experimental em Camundongos”. Revista do Instituto de Medicina Tropical de São Paulo, 8, pp. 219-224, I966.

BRAsIl, A. "Aperistalsis of the Esophagus". Revista Brasileira de Gastroenterologia, I, pp. 2I-44, I955.

Chagas, C. "Moléstia de Carlos Chagas: Segunda Conferência na Academia Nacional de Medicina em Agosto de r9ı I”. Coletânea de trabalhos científicos. Brasília, Ed. da UnB, I98I, pp.I67-I92.

“Tripanosomíase Americana: Forma Aguda da Moléstia”. Memórias do Instituto Oswaldo Cruz, 8, pp. 37-69, I916.

Chagas, C. \& Villela, E. “Forma Cardíaca da Trypanosomiase Americana”. Memórias do Instituto Oswaldo Cruz, I4, pp. 5-6I, I922.

Correa Neto, A. “Achalasie du pylore chez l'adulte”. Presse Médicale, I 2, pp. I48-I 53 , I940.

. Patogenia, Diagnóstico e Tratamento do Megaesôfago (Mal de Engasgo). São Paulo, Cia. Editora Nacional, I935.

. "Relaciones Patogénicas y Concomitância de Megaesófago y Megacolon”. Revista de Cirugia de Buenos Aires, I3, pp. 72I-735, I934.

Correa Neto, A. \& Etzel, E. "Le megaesophage et le megacôlon devant la theorie de l'Achalasie. Étude clinique et anatomo-pathologique”. Revue Sud-Américaine de Médicine et de Chirurgie, 5 (7), pp. 395-420, I934.

Costa, M. "Salubridade, Epidemias e Moléstias Reinantes". In Wappaeus, J. E. Geographia Physica do Brasil. Rio de Janeiro, G. Leuzinger \& Filhos, I 884.

Etzel, E. “A Avitaminose como Agente Etiológico do Megaesôfago e do Megacolo”. Anais da Faculdade de Medicina da Universidade de São Paulo, I I, pp. 59-85, I935. 
. "Neuropatologia do Megaesofago e do Megacolo: Estudo de 5 Casos". Anais da Faculdade de Medicina da Universidade de São Paulo, Io, pp. 63 I-650, I934.

Freitas, J. L. P. de. “Comentário aos Trabalhos Apresentados ao 8 Congresso Médico do Triângulo Mineiro e do Brasil Central sobre o Tema: Estado Atual da Doença de Chagas em Goiás". Revista Goiana de Medicina, 2, pp. 31 5-320, I956.

. Contribuição para o Estudo do Diagnóstico da Moléstia de Chagas por Processos de Laboratório. Tese da Faculdade de Medicina da USP, I947.

Guimarães, J. P. \& Miranda, A. "Megaesôfago em Macaco Rhesus com io Anos de Infecção Chagásica”. Anais do Congresso Internacional sobre a Doença de Chagas (I959), vol. II, pp. 657-67I, I96I.

Ingelfinger, F. Annals of 2nd World Congress of Gastroenterology - Vol. I: Topical Problems in Achalasia of the Esophagus. Basel, S.Karger, I963.

Kidder, D. P. \& Fletcher, J. C. O Brasil e os Brasileiros. Coleção Brasiliana, vol. 205-A, São Paulo, Cia. Editora Nacional, I94I.

Koeberle, F. "Chagaskrankheit: Eine Erkrankung der neurovegetativen Peripherie”. Wien Klinisch Wochenschrift, 68, pp. 333-339, I956.

. "El Mal de Chagas: Enfermedad del Sistema Nervioso". Revista Medica de Cordoba, 47, pp. 105-I33, I959. . "Megaesophagus". Gastroenterology, 34, pp. 460-465, I958.

."Megacolon”. The Journal of Tropical Medicine and Hygiene, 6I, pp. 2 I-24, I 958. "Moléstia de Chagas: Enfermidade do Sistema Nervoso". Anais do Congresso Internacional sobre a Doença de Chagas (Rio de Janeiro, I 959), 2, pp. 69 I-7 I 6, I96ra. "Patogenia da Moléstia de Chagas: Estudo dos Órgãos Musculares ôcos." Revista Goiana de Medicina, 3, pp. I 55-I80, I957.

. "Patologia do Megacolo Adquirido". Anais do I ${ }^{\circ}$ Congresso Latinoamericano, $2^{\circ}$ Internacional e I $0^{\circ}$ Brasileiro de Proctologia, I, pp. 269-277, I960.

. "Patologia y Anatomia Patológica de la Enfermedad de Chagas". Boletin de la Oficina Sanitaria Panamericana, 5I, pp. 404-428, I96Ib.

"Patologische Befunde an den muskularen Hohlorganen bei der experimentellen Chagaskrankheit”. Zentralblatt fur allgemeine Pathologie und pathologische Anatomie, 95, pp. 32I-329, I956.

Koeberle, F. \& Alcantara, F. G. de. “Mecanismo da Destruição Neuronal do Sistema Nervoso Periférico na Moléstia de Chagas”. O Hospital, 57, pp. I057-I062, I960. Koeberle, F. \& Nador, E. "Etiologia e Patogenia do Megaesôfago no Brasil”. Revista Paulista de Medicina, 47, pp. 643-66I, I955. 
Langgaard, T. J. H. Diccionario de Medicina Domestica e Popular. Rio de Janeiro, Eduardo \& Henrique Laemmert, I873.

Laranja, F.; Dias, E. \& Nóbrega, G. “Clínica e Terapêutica da Doença de Chagas”. Memórias do Instituto Oswaldo Cruz, 46, pp. 473-529, I948.

Martins, A. V.; Versiani, V. \& Tupinambá, A. A. "Estudos sobre a Moléstia de Chagas no Estado de Minas Gerais: II. Sobre I 56 Xenodiagnósticos Feitos em Belo Horizonte”. Arquivos do Instituto Químico-Biológico, I, pp. 63-70, I 945.

Meneghelli, U. G. “O ‘Mal de Engasgo’ em Innocencia: As Possíveis Fontes de Informações do Visconde de Taunay”. Revista Goiana de Medicina, 38, pp. I-9, I992.

Meneghelli, U. G.; Rezende, J. M. de; Troncon, L. E. de; Madrid, N. \& Moura, M. L. P. de. "Um Nome que Faltava na História do Megaesôfago Chagásico: Joseph Cooper Reinhardt (I809/IO-I873)”. Arquivos de Gastroenterologia, 35, pp. I-8, I 998.

Neiva, A. \& Penna, B. "Viagem Científica pelo Norte da Bahia, Sul do Piauí e de Norte a Sul de Goiás”. Memórias do Instituto Oswaldo Cruz, 8, pp. 74-224, I9I6.

Nunan, B.; Rezende, C. L. \& Canelas, A. "Megaesôfago e Doença de Chagas". Anais da 6a Jornada de Puericultura e Pediatria. Belo Horizonte, pp. 633-636, I952.

Okumura, M. "Contribuição para o Estudo dos Neurônios do Plexo Mientérico do Colo na Moléstia de Chagas Experimental do Camundongo Branco (Mus musculus)”. Revista do Hospital das Clínicas, 22, pp. I92-203, I967.

Paranhos, U. “Considérations sur le mal d'engasgo”. Bulletin de la Societe de Pathologie Exotique, 7, pp. 47-50, I913.

PARISI, R. Contribuição ao Estudo do Mal de Engasgo e seu Tratamento Cirúrgico. Tese da Faculdade de Medicina de São Paulo, I925.

Porto, C. \& Porto, C. C. "História do Megaesôfago nos Congressos Médicos do Brasil Central". Revista Goiana de Medicina, I6, pp. I I7-I36, I970.

Raia, A. Acalásia do Piloro. Tese da Faculdade de Medicina de São Paulo, I943.

Ramos, J. "Electrocardiographie chez les malades atteints de megaesophage et megacolon”. Folia Clinica et Biologica, 7, pp. I49-I6I, I935.

Ramos, J. \& Oria, J. “Clínica e Histopatologia do Coração em Portadores de Megaesôfago e Megacólon”. Arquivos de Cirurgia Clínica e Experimental, 4, pp. 363-442, I940.

Resende, C. L. de, Pellegrino, J. \& Canelas, A. "Inquérito sobre a Doença de Chagas em Crianças Internadas em Hospitais de Belo Horizonte (Minas Gerais, Brasil)”. O Hospital, 43, pp. 24I-250, I953. 
Rezende, J. M. de. “Alterações do Tubo Digestivo na Moléstia de Chagas”. Anais do Congresso Internacional sobre a Doença de Chagas. Rio de Janeiro, pp. I407-I426, I963.

. "Forma Digestiva da Moléstia de Chagas". Revista Goiana de Medicina, 5, pp. 193-227, I959.

. “Manifestações Digestivas da Doença de Chagas”. In Dani, R. \& Castro, L.

P. Gastroenterologia Clínica, $3^{\underline{a}}$ ed. Rio de Janeiro, Guanabara Koogan, I993.

. "Megaesôfago por Doença de Chagas". Revista Goiana de Medicina, 2, pp. 297-3 I4, I956.

Rezende, J. M. de; Lauar, K. L. \& Oliveira, A. R. de. “Aspectos Clínicos e Radiológicos da Aperistalsis do Esôfago". Revista Brasileira de Gastroenterologia, I 2, pp. 247-262, 1960.

Spix, J. B. \& Martius, C. F. Viagem pelo Brasil. vol. 2, Belo Horizonte/ São Paulo, Ed. Itatiaia/Edusp, I98I.

Tafuri, W. L. \& Brener, Z. “Lesões do Sistema Nervoso Autônomo do Camundongo Albino na Tripanosomíase Experimental na Fase Aguda”. O Hospital, 69, pp. 37I-383, I966.

Tafuri, W. L.; Maria, T. A. \& Lopes, E. R. "Lesões do Plexo Mientérico do Esôfago, do Jejuno e do Colo de Chagásicos Crônicos: Estudo ao Microscópio Eletrônico”. Revista do Instituto de Medicina Tropical de São Paulo, I3, p. 76, I97 I.

Taunay, A. d'E. "Viagem de Regresso de Mato-Grosso à Corte". Revista do Instituto Historico, Geographico e Ethnografico do Brasil, 32, pp. 5-5 I, I 869. . Inocência. $38^{\mathrm{a}}$ ed. Melhoramentos, São Paulo, I97I.

Toledo, P. de A. "Acalásia e Moléstia de Chagas". Anais Paulistas de Medicina e Cirurgia, 102, pp. 266-276, I975.

VAmpré, E. Contribuição ao Estudo do Mal de Engasgo. Serviço Sanitário do Estado de São Paulo, vol. 5, I919.

. “Terceira Contribuição ao Estudo do Mal de Engasgo”. Brazil-Médico, 37, pp. I37-I 58 , I923.

Villela, E. “A Ocorrência da Moléstia de Chagas nos Hospitais de Belo Horizonte e na População de seus Arredores. Boletim da Academia Nacional de Medicina, I02, pp. I 22-I 56, I930. 